\title{
تأثير التدريبات النوعية على بعض المتغيرات البذنية والفسيولوجية في السباحة لأطفال متلازمة داون (المنغوليين)
}

* أ. أ. د / أثرف إبراهيم عبدالقادر

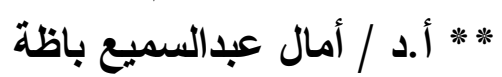

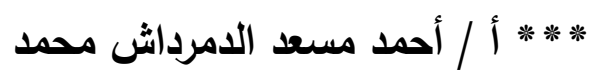

مقدمة البحث : - 20

ويشير سمير العجمي 2007م نقلا عن كريستي بروند Kristy Prond إلى وجود عدة

اتجاهات حديثة في التعليم والتدريب تؤكد على أهمية استخدام التمرينات النوعية والتي ينتابه فيها المسار الزمني للمجموعات العضلية العاملة operant في التمرين بالمسار الزمني لنفس المجموعات العضلية والمسئولة أيضا عن أداء المهارة. (11:7 (11)

من ناحية أخرى يذكر عادل عبد البصير 1985م أن التمرينات النوعية المشابهة للأداء

المهاري هي جزء من الدعامة الأساسية التي يرتكز عليها المبتدئ لإمكانية تعلمه المهارات الأساسية والوصول به إلى أعلى مستوى ممكن. (32: (32)

كما يضيف عماد السرسي 2001م أن استخدام التمرينات النوعية المشابهة للأداء المهاري

يسهم بدرجة كبيرة في تحسين أداء المهارات الحركية أثناء المباريات. (12 : 157) تعد التمرينات داخل الماء متشابه للتمرين خارج الماء ولكنها أسهل فالماء له مواصفات فيسيلوجية تساعد على الطفو، كما ان الانسان حين يكون وسط الماء يخسر من ثلاثة ارباع وزنه فيقل الوزن والحمل والنتل على عضلاته وعظامه ومفاصله فتسهل عليه الحركة مقارنة بالحركة خارج الماء، وحرارة الماء الدافئ تساعد على ارتخاء العضلات وبالتالي تصبح الحركة أقل ألما وأسهل.

وقد وصف العالم جون داون هذه الحالة (متلازمة داون) والذي يرجع التسمية إلى اسمه أنهم أطفال يولدون بملامح مميزة أهمها الأعين المائلة، والرأس المستدير صغير الجسم نسبياً،

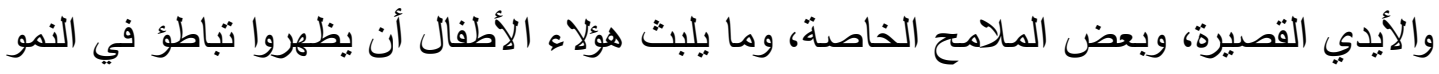

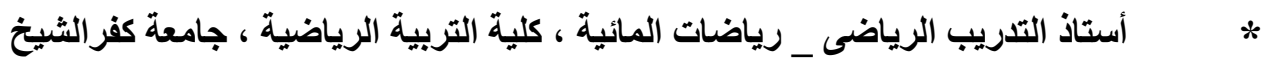

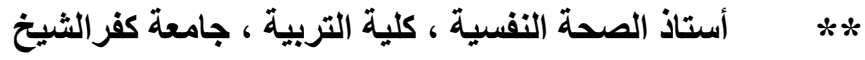

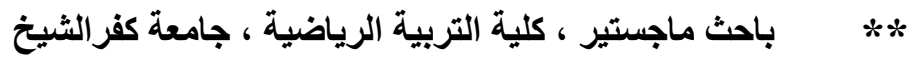


الحركي ، وتأخر في القرات العقلية، يذكر أنه في العام (1959م)، اكتشف العلماء خلل الكروموسومات المسبب لهذا المرض. (13: 18)

ومن ناحية أخري أثتتت العديد من الدراسات فاعلية وأثر برامج الرعاية لدي الأطفال المصابين لمتلازمة داون في تحقيق السلوك التكيفي منل دراسة بن قيدة، 2008م التي توصلت إلي وجود فروق دالة إحصائيا فيما يخص درجات التصرفات الاستقلالية لدى الأطفال ذوبي متلازمة داون قبل تلقيهم للبرنامج و بعد مرور فتزة من تلقيهم إياه، كما أثثبت الدراسة التي استهدفت التعرف على ثأثير برنامج تأهيلي مقترح على بعض المتغيرات البدنية لدى الأطفال المصابين بشلل الأطفال المخى أن للبرنامج الثأهيلي المقترح اثر ايجابي على المتغيرات البدنية قيد البحث (النوازن- المرونة) وعلى أطالة العضلات المصابة بالتشنج. (15: 55)

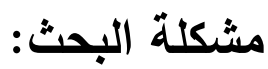
يشهد العالم تقدم علمي كبير في مجالات الحياة المختلفة بصفة عامة ومجال التربية الرياضية بصفة خاصة فلقد تطور المستويات الرياضية نطورا كبيرا نتيجة للدراسات والبحوث العلمية وتطور الأجزة العلميو والأدوات المساعدة في مجال التربية الرياضية وذلك من اجل

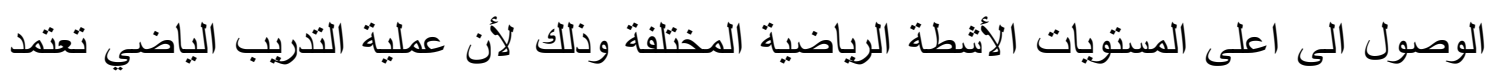
على التخطيط العلمي السليم وذللك لهدف الوصول بالفرد الرياضي إلى تحقيق أعلى مستوى في نوع النشاط الرياضي.

ومما لا شك فيه ان التدريب في وجود وسط مائي يساهم في تحسين الأداء الحركي لاى أطفال الداون (المنغوليين) وخاصة من هم ذو مشاكل في الحركة بشد او توتز في العضلات في وقت أقل مما يستهلك في العلاج الطبيعي هذا ويرى الباحثون ان التعرف على نأثير التدريب في دي وجود وسط مائي هو الطريق الاقل لرفع المستوى الحركى و البدني لدى هؤلاء الاطفال لذلك من خلال خبرة الباحثون كمدربين ومتخصصين فى مجال السباحة و كاخصائي تاهيل حركي منذ عشرة أعوام في مراكز عديدة وفي اندية كثيرة لاحظوا ان كثير من الاخصائيين يههلون التدريبات و السباحة لهؤلاء الاطفال فى التدريب داخل الوسط المائى مع أن هنالك تحسن ملحوظ فى الحركة للأطفال مما يؤثر على نجاح التجربة. 


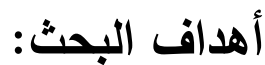

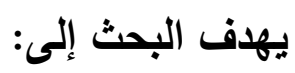

- التعرف على تأثير التدريبات النوعية على بعض المتغيرات البدنية والفسيولوجية في السباحة لأطفال متلازمة داون (المنغوليين)

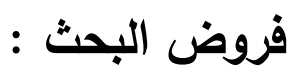

- - توجد فروق ذات دلالة إحصائية بين متوسطي رثب المجموعة التدريبية في القياسين القبلي والبعدي على مقياس بعض المتغيرات البدنية (الإتزان، قوة عضلات الظهر، قوة عضلات الرجلين) بعد تطبيق البرنامج في القياس البعدي". - توجد فروق ذات دلالة إحصائية بين متوسطي رتب المجموعة التدريبية في القياسين القبلي والبعدي على مقياس بعض المتغيرات الفسيولوجية (النبض، السعة الحيوية، أقصى إستهلاك للأكسجين) بعد تطبيق البرنامج في القياس البعدي".

أهمية البحث:

1. - الأهمية العلمية للبحث:

- قد يساهم البحث فى تحسين مستوى الحركات الاساسيه لدى الاطفال المصابين بمتلازمة

$$
\text { داون (المنغوليين). }
$$

- قد يساهم البحث في تحسين مستوى القدرات البدنيه لدى الاطفال المصابين بمتلازمة داون (المنغوليين) - محاولة الوصول بلطفل المصاب بمتلازمة داون الى مستوى مقارب الى الاعتماد على الى النفس فى تلبية إحتياجاته.

- - توفير برنامج تدريسى مائى يساعد على تتمية الحركة البدنية لاى اطفال متلازمة داون.

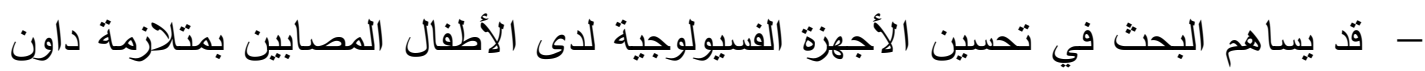
(المنغوليين)

\section{2 الاهمية التطبيقية للبحث:}

قد يساعد هذا البحث فى تقديم برنامج تدريبى على المتغيرات البدنيه والفسيولوجية ورفع

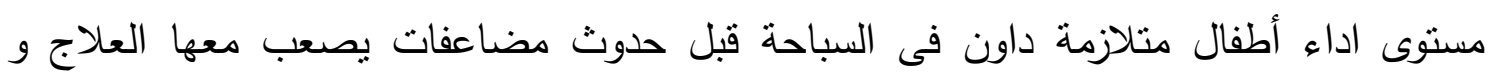
التاهيل بأساليب الطب الطبيعى والتاهيل البدنى دون الحاجة للتنخل الجراحى. 
المصطلحات المستخدمة فى البحث :

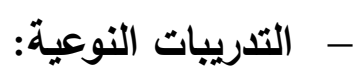

هي "التمرينات التي تؤدى بصورة تتفق مع طبيعة الأداء للمهارة الحركية باستخدام المجموعة

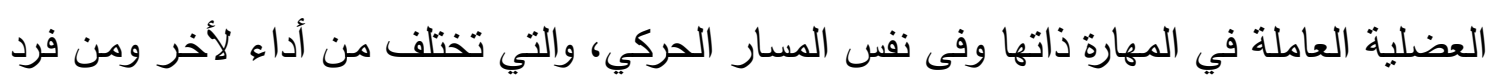

$$
\text { - لأخر". (17 : 8) }
$$

يذكر عادل عبد البصير 1996 أن اللياقة البدنية العامة هى ذلك النوع من النشاط الحركى الذى يكسب الفرد القدرة على أداء منطلبات الحياة اليومية بكفاية إلى جانب توفر بعض الطاقات التى تلزم للتمتع بوقت الفراغ ومواجهة الظروف الطارئه فى حياته اليومية. (90 (50)

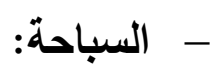
يمكن تعريفها على أنها إحدى أنواع الرياضات المائية التى تستخدم الوسط المائى كوسيلة للتحرك فيه وذلك عن طريق تحريك الذراعين والرجلين والجذع من أجل رفع مستوى كفاءة الفرد من الناحية الجسمية والعقلية والاجتماعية (تعريف إجرائى) - متلازمة داون: هذه الحالة (متلازمة داون) والذي برجع التسمية إلى اسمه أنهم أطفال يولدون بملامح مميزة أهمها الأعين المائلة، والرأس المستدير صغير الجسم نسبياً، والأيدي القصيرة، وبعض المض الملامسح الخاصة، وما يلبث هؤلاء الأطفال أن يظهروا تباطؤ في النمو الحركي، وتأخر في القدرات العقلية،

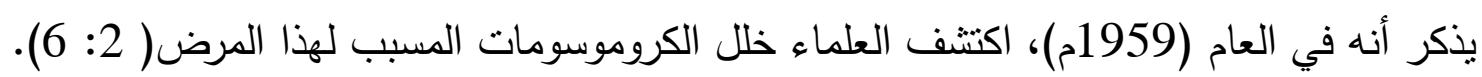
حالة جينية ناتجة عن وجود كروموسوم زائد في الخلية، وهو يعني أن صاحبها لديه (47) كروموسوماً بدلا من (46)، وهي تحدث نتيجة خلل جيني في نفس وقت حدوث الحمل أو أثنائه وليست حالة مرضية ولا يمكن علاجها وعادة تكون مصحوبة بتخلف عقلي. (13، 8) الإطار النظري: - (الن 
ويثير كل" من عبد المنعم برهم ومحمد أبو نمره 1988م أن التمرينات النوعية يقصد بها التمرينات التي تكون وسيلة أساسية لتحقيق هدف مقصود، فهي تشكل العامل الأساسي المساعد في تعليم المهارات الحركية لكثير من الأنشطة الرياضية. (32:10) ويتفق كل" من محمد علاوي 1990م وعصـام عبد الخـالق 1994م على أن التمرينات النوعية هي الحركات التي تتثابه في تكوينها الحركي مع الحركات التي يؤديها اللاعب في غضون المنافسة الرياضية من حيث (القوة، السرعة، المسار الزمني للقوة، وكذللك اتجاه العمل العضلي)، ولذلك فهي تعتبر وسيلة مباشرة للإعداد الرئيسي لأي لاعب من حيث التوافق الحركي وتتابع مسار الأداء الحركي واتجاهه. وتحتوى التمرينـات النوعيـة على حركـات مشـابهة لـلأداء الفنـي الأساسي للتهـرين وذلـك باستخدام نفس العضلات العاملة في الأداء المهاري المطلوب وله الأثر الفعال في سرعة التعليم، وتستخدم التمرينات النوعية لتتمية وتطوير الأداء الصحيح للمهارات الحركية الأساسية، كما أنه لمن الأهميـة الاسـتعانة بالتمرينـات التــي تـؤدى بصـورة تتفـق مـع طبيعـة الأداء للمهـارة باسـتخدام المجموعات العضلية العاملة في المهارة ذاتها وفي نفس المسار الحركي والزمني والمكاني ، مما يكون لـه أفضل الأثر في تحسين الصفات البدنية وبالتالي تحسين مستوى الأداء المهاري حيث يحتاج التدريب إلى تحسين صفات بدنيـة خاصـة تتحقق عن طريق التمرينـات المشابهة لـلأداء وتعتبر التمرينات النوعية احد أهم الوسائل التي تستخدم في التعليم والتدريب. (16 : 7) (5: 12) يذكر "جان كاتز Jane Katz " 1995م إنه مع زيادة الاهتمام بممارسة السباحة من خلا السبعينيات والثمانينيات والتطور الهائل فى طرق التدريب الدختلفة أظهرت الحاجة لتدريبات لتتمية اللياقة البدنية التى تجمع مـا بين تتمية الإطالة والقوة القدرات الهوائية، وذلك دون حدوث مخاطر على المفاصل والأطرف، ومن هنا توجهت الأنظار للتمرينات المائية والتى يتت من خلالها ابتكار تمرينات تتقل وسط التمرين من الأرض إلى الماء، وبناء على ذلك ظهرت برامج التمرينات المائية والتى أطلق عليها hydro - calisthemics ثم أطلق عليها hydro - slimmastics هذا ويمكن وصف برامج التمرينات المائية على انها برامج التمرينات الأرضية الأصل وعدلت لتصبح مائية، حيث إنه ومن المعروف أن للماء خصائص مختلفة عن خصائص الهواء وبناء على ذلك فأن طريقة الأداء للتمرينات المائية تكون مختلفة عن تلك التى تؤدى على الأرض، والجدير 
بالذكر أنه أصبحت التمرينات المائية التى تستهدف تحسين اللياقة البدنية معترف بها وذات انتشار واسع فى الأندية الرياضية والنوادى الصحية. (18: 4) ويشير بورنستون Borensteion (1996م) إلى أن التمرينات التأهلية ضد مقاومة هي التي حركات بنائية ومحكمة للجسم لتعديل حركته وتحسين الوظائف العضلية، والحفاظ على بناء جيد للجسم، والتمرينات تزيد القوة العضلية والمرونـة ومدى الحركة والتحمل، ووصف التأهيل الحركي يجب أن يكون له هدف محدد، ويتم تعديل البرنامج الثأهيلي حسب حالة المريض. (19: 446) ويثشير أستراند Astrand م إلى أن منوسط الحد الأقصى النسبي لإستهلاك 1977 الأكسجين لدى الرجل السليم وظيفيًا في سن العشرين يصل إلى 56 ملليلتر/كجم/ق ، ويرتفع هذا المتوسط إلى أكثر من 80 ملليلتر/كجم/ق تبعا للحالة التدريبية التي يصل إليها الفرد الرياضي.

ويضيف حسام فاروق 1997م بأن التمرينات المائية هى تمرينات بدنية تؤدى فى الماء إما

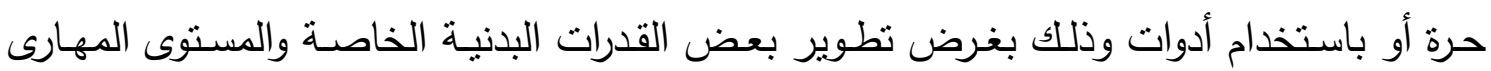
لطرق السباحة المختلفة. (6: 7 ) أهم خواص الماء التى تحقى أفضل الآثار على الجسم هى:

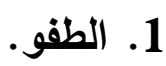

اتجاه الطفو عكس اتجاه الجاذبية الأرضيه يسمح للجسم بالتحرك بسهولة ويسر عن اليابسة.

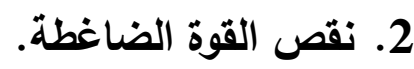
كلما زاد عمق الفرد فى الهاء قلت تبعاً لذللك القوة الضـاغطة أو قوة تقل الوزن على كل المفاصل وكذلك غضاريف فقرات العمود الفقرى. 3. الضغط الهيدروستاتيكى على أجزاء الجسم الغاطس.

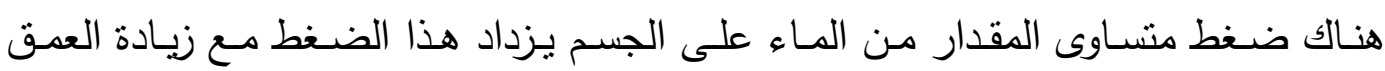

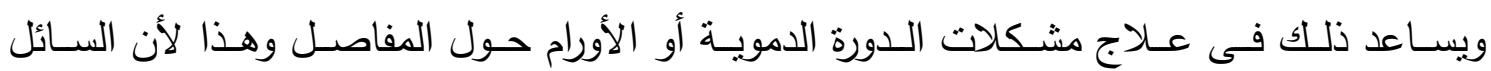

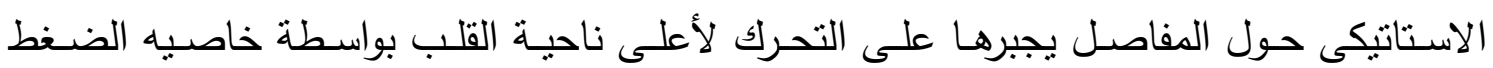
الهيدورستاتيكى (11:4) Hydrostatic Pressure 
1. دراسة أحمد محمد رشدي إبراهيم عسر (2017) (2): بعنوان أثر برنامج النأهيل المقترح

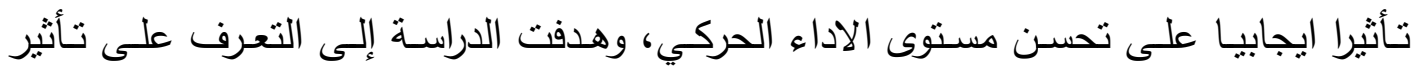

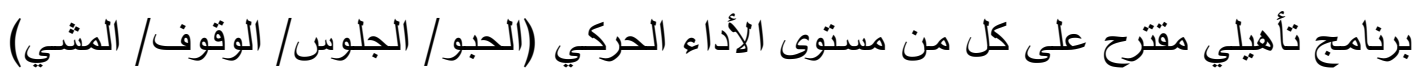

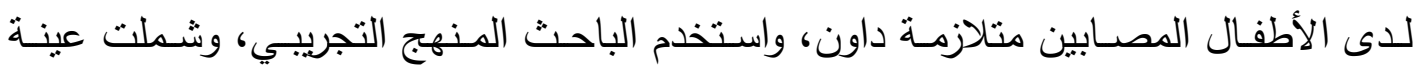

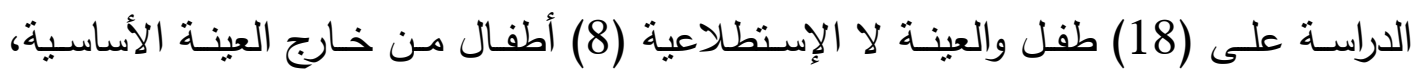
وكانت أهم النتائج أثر استخدام برنامج تأهيلي على مستوى الأداء الحركي لاى أطفال متلازمة داون.

2. دراسة احمد خضر، (2015)(1): بعنوان "برنامج تأهيلي لتحسين درجه تثوه النقعر القطني

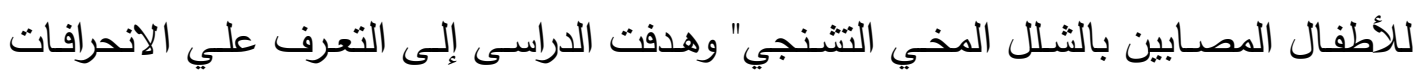

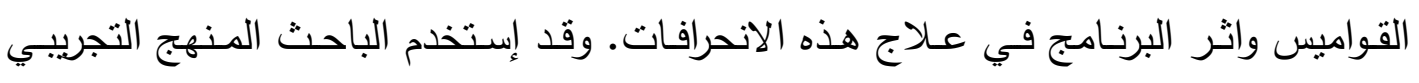

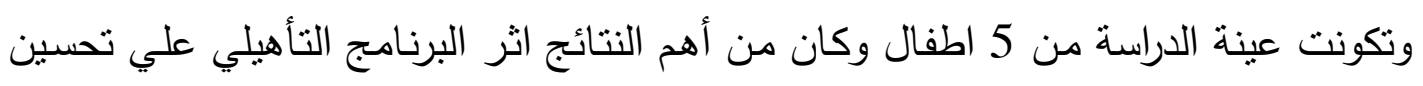
درجه تتثوه التقعر القطني للأطفال الدصابين بالثلل المخي التثنبجي. 3. دراسة سهام فاروق إسماعيل مهدي (2009)(8): بعنوان تحسن في مستوي المتغيرات

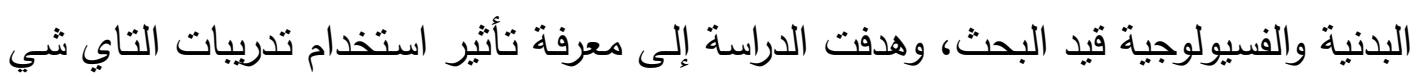
شوان المائية علي بعض المتغيرات البدنية والفسيولوجية لاي طالبات كلية التربية الرياضية،

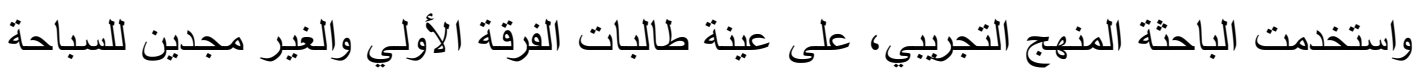

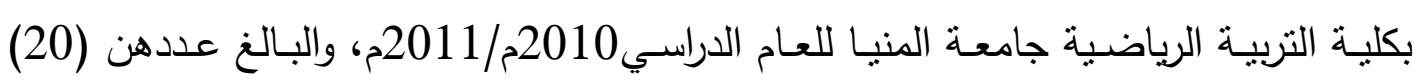

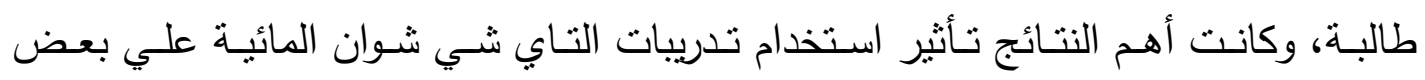
التنغيرات البنية والفسيولوجية لدي طالبات كلية التربية الرياضية.

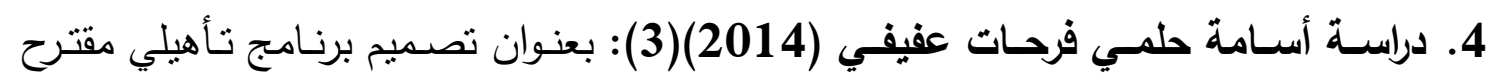

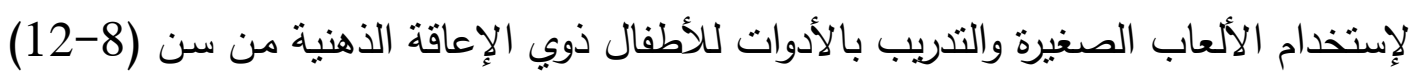
سنة، هدفت الدراسة إلى دراسة التعرف على تأثير البرنامج التأهيلي الدقترح لتحسين بعض التابل

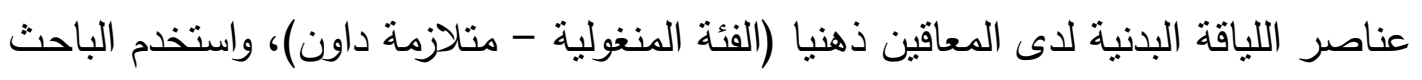

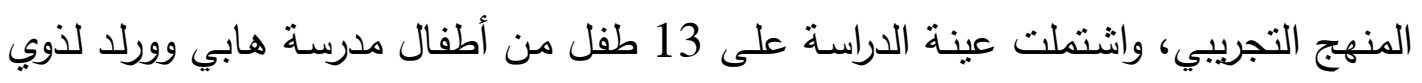


الإحتياجات الخاصـة التابعة لمدينة الثـروق (8) أطفال للعينة الأساسية (5) ألطفال للعينـة الإستطلاعية ويتراوح عمرهم من (9-12) سنة وكانت أهم النتائج التعرف على تأثثر البرنامج التأهيلي المقترح لتحسين بعض عناصر اللياقة البدنية لدى المعاقين ذهنيا (الفئة المنغولية متلازمة داون)، فاعلية البرنامج في تحسين القدرات البدنية لأطفال المصابين بمتلازمة داون

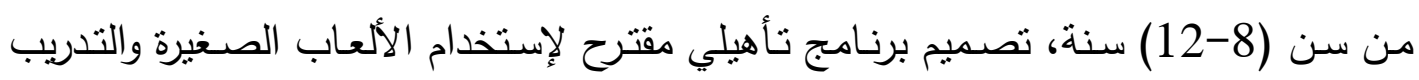
بالأدوات للأ"فال ذوي الإعاقة الذهنية من سن (8-12-12) سنة.

\section{مدى الاستفادة من الدراسات المرجعية:}

فى ضوء تحليل أهم النتائج والإجراءات المتبعة بالدراسات السابقة إستخلص الباحثون عدة نقاط هامة للإستعانة بهم فى هذا البحث: - - إستخدام المنهج التجريبى هو الأسلوب الأمتل لتحقيق الهدف من تلك الدراسة. - تحديد وسائل وأدوات جمع البيانات المناسبة لطبيعة البحث. - - تحديد الطريقة المتلى لإختيار عينة البحث. - تحديد أنسب المعالجات الأحصائية التى تتفق مع أهداف وعينة البحث. - مراعاة أسس وضع البرنامج التدريبى التأهيلى.

- تحديد الإختبارات والقياسات البدنية المستخدمة فى الدراسة الحالية. - الأستفاده من نتائج الأبحاث فى تحسين المتغيرات البدنية فى السباحة لأطفال متلازمة داون. إجراءات البحث : (1) منهج البحث :

إستخدم الباحثون المنهج التجريبي لتضم القياس القبلي والبيني والبعدي لمجموعة تجريبية واحدة عينة البحث.

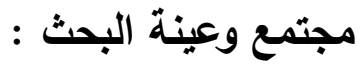
تم اختيار عينة البحث بالطريقة العديـة من أطفال الداون او (المنغوليين) وعددهم 20 
جدول (1)

توصيف عينة البحث

\begin{tabular}{|c|c|c|}
\hline النسبة المئوية & العدد & \\
\hline$\% 73$ & 8 & العينة الأساسية \\
\hline \%27 & 3 & العينة الاستطلاعية \\
\hline$\% 100$ & 11 & إجمالي العينة \\
\hline
\end{tabular}

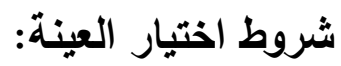

- - توافر عدد كافي لاجراء البحث.

- مقوع عينة البحث في مجتمع اقليمي واحد ومتقارب.

- عمل الباحثون كمدبين ومتخصصين فى مجال السباحة.

- موافقة اداره النادي علي تطبيق البحث.

- موافقة أولياء الأمور علي تطبيق الدراسة علي أنجالهم. - - أن يكون من الممارسين والغير الممارسين للنشاط الرياضى. - - أن يكون غير خاضعين لبرنامج علاجى أخر سواء كان (تأهيلى _ طبى). - الإنتظام فى البرنامج المقترح خلال فترة إجراء البرنامج المطبق.

جدول (2)

التوصيف الإحصائى لعينة البحث في المتغيرات المختارة قيد البحث (الإعتدالية) $8=\dot{0}$

\begin{tabular}{|c|c|c|c|c|c|c|}
\hline الإلتواء & المعيـاري & الوسيط & الحستوسب & والقياس & المتغيـــــــرات & \\
\hline \multicolumn{7}{|c|}{ المتغيرات الأنثروبومترية } \\
\hline 0.58 & 7.09 & 148.00 & 149.40 & سم & الطـول & 1 \\
\hline 0.28 & 5.01 & 40.00 & 41.50 & كجم & الـــــوزن & 2 \\
\hline 0.17 & 0.29 & 11.58 & 7.02 & سنة & العمر الزمنـي & 3 \\
\hline \multicolumn{7}{|c|}{ المتغيرات البلنية } \\
\hline $0.27-$ & 1.41 & 20.00 & 19.53 & $\dot{\Delta}$ & الاتزان & 4 \\
\hline 0.10 & 1.67 & 18.00 & 18.20 & كجم & قوة عضلات الظهر & 5 \\
\hline 0.82 & 2.29 & 48.10 & 48.25 & كجم & قوة عضلات الرجلين & 6 \\
\hline \multicolumn{7}{|c|}{ المتغيرات الفسيولوجية } \\
\hline 0.23 & 1.52 & 16.66 & 16.53 & ن ن اق & النبض في الراحة & 7 \\
\hline $0.29-$ & 1.75 & 36.38 & 35.86 & $\dot{H}$ & السعة الحيوية & \\
\hline $0.68-$ & 0.40 & 12.27 & 12.10 & م. & اقصى استهلاك للاوكسجين & \\
\hline
\end{tabular}


يتضـح من الجدول (2) أن معاملات الإلتواء لمجتمع البحث في المتغيرات المختاره قيد البحث

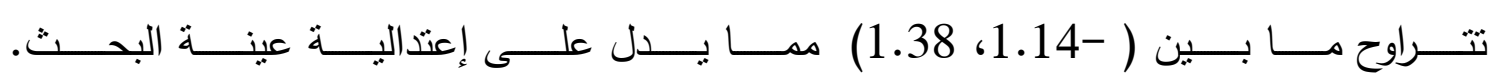
وسائل جمع البيانات:

المراجع والدراسات المرتبطة بالبحث:

تتلخص وسائل جمع البيانات التي إستعان بها الباحثون في تتفيذ هذا البحث في (الكتب والمراجع العلمية - الدراسات العلمية السابقة - المجلات العلمية المتخصصة- شبكة المعلومات الدولية الإنترنت من خلال المواقع المتخصصة في السباحة). القياسات والإختبارات المستخدمة قيد البحث. أ- القياسات الانثروئيومترية - - - - السن. -

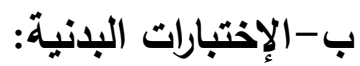
- قياس النوازن الثابت (الوقوف علي قدم واحدة). - قياس قوه عضلات الظهر. - - مياس قوه عضلات الرجلين.

ت- الأدوات والأجهزة Tools and Equipment. - - جهاز الرستاميتز Restameter لقياس الطول (سم). - ميزان طبي لقياس الوزن (كجم). - - جهاز سبيرومينز جاف (إلكتروني) سيرن) - جهاز الديناموميتز Dynamometer لقياس قوه عضلات الظهر والرجلين (كجم). - شريط قياس معاير لقياس المسافات (سم).

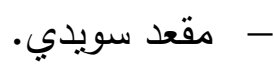




$$
\begin{aligned}
& \text { - مكعبات خثبية. } \\
& \text { - لوح خشبى عرضة 20سم. } \\
& \text { - كرات سويسريه (كرات التمرينات المطاطية). } \\
& \text { - - الأستيك المطاط. } \\
& \text { - الإنبوب المائي. } \\
& \text { - } \\
& \text { - - بور وكتفات. } \\
& \text { - أطواق مختلفة المقاسات. } \\
& \text { - ساعة إيقاف. } \\
& \text { - جهاز قياس النبض pulse oximeter - } \\
& \text { - جهاز قياس أقصى إستهالك للأكسجين vo2max - } \\
& \text { المعالجات الإحصائية }
\end{aligned}
$$

تم إجراء المعالجات الإحصائية باستخدام برنامج الحزم الإحصائية Spss باستخدام الحاسب الآلى وذللك من خلال المعالجات الإحصائية التالية:

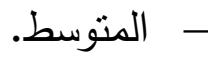

$$
\begin{aligned}
& \text { - الإنحراف المعياري. }
\end{aligned}
$$

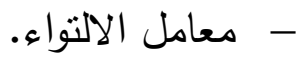

$$
\begin{aligned}
& \text { - إختبار (ت) لعينتين مستقلتين، إختبار (ت) لعينتين مرتبطتين. } \\
& \text { - معامل الإرتباط لبيرسون. }
\end{aligned}
$$

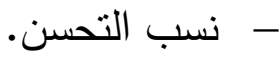

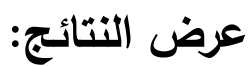

1. نتائج الفرض: والذي ينص على "توجد فروق ذات دلالة إحصائية بين متوسطى رتب المجموعة التجريية في القياسين القبلي والبعدى على مقياس بعض المتغيرات الفسيولوجية (النبض في الراحة، السعة الحيوية، أقصى استهلاك للاوكسجين) بعد نطبيق البرنامج في اتجاه

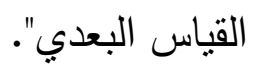


للتحقق من هذا الفرض قام الباحثون بحساب دلالة الفروق باستخدام اختبار (ويلكوكسون)

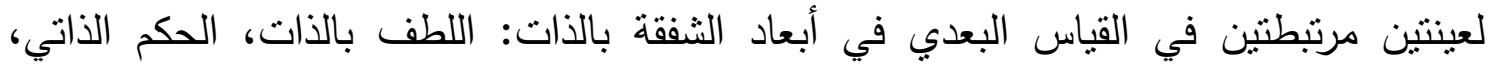
الانسانية المشتركة، العزلة، اليقظة العقلية، التوحد المفرط، والدرجة الكلية، كما يتضح من الجدول

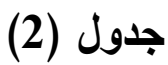

دلالة الفروق بين متوسطي رتب القياسين القبلي والبعدي للمجموعة التجريبية في بعض المتغيرات الفسيولوجية (النبض في الراحة، السعة الحيوية، أقصى استهلاك للاوكسجين)

\begin{tabular}{|c|c|c|c|c|c|c|c|c|c|}
\hline مستوى الالالة & $\begin{array}{l}\text { قيمة } \\
Z\end{array}$ & مجموع الرتب & متوسط & ن & الرتب السالبة & $\varepsilon$ & b & القياس & الفتسيوليرات \\
\hline \multirow{4}{*}{0.05} & \multirow{4}{*}{2.52} & 36.00 & 4.50 & 8 & الرتب السالبة & \multirow{4}{*}{2.17} & \multirow{4}{*}{$\begin{array}{l}68.36 \\
60.81\end{array}$} & \multirow{4}{*}{ القبلي } & \multirow{4}{*}{ النبض في } \\
\hline & & 0.00 & 0.00 & 0 & الرتب الموجبة & & & & \\
\hline & & & & 0 & العلاقات & & & & \\
\hline & & & & 8 & الاجمالي & & & & \\
\hline \multirow{4}{*}{0.05} & \multirow{4}{*}{2.52} & 0.00 & 0.00 & 0 & الرتب السالبة & \multirow{2}{*}{2.11} & \multirow{2}{*}{63.90} & \multirow{2}{*}{ القبلي } & \multirow{4}{*}{ الحيوية } \\
\hline & & 36.00 & 4.50 & 8 & الرتب الموجبة & & & & \\
\hline & & & & 0 & العلاقات & \multirow{2}{*}{2.01} & \multirow{2}{*}{64.70} & \multirow{2}{*}{ البعدي } & \\
\hline & & & & 8 & الاجمالي & & & & \\
\hline \multirow{4}{*}{0.05} & \multirow{4}{*}{2.52} & 36.00 & 4.50 & 8 & الرتب السالبة & \multirow{4}{*}{$\begin{array}{l}2.68 \\
1.18\end{array}$} & \multirow{4}{*}{$\begin{array}{l}34.04 \\
27.11\end{array}$} & \multirow{4}{*}{ القبلي } & \multirow{4}{*}{ للاستهلاكى أقصى } \\
\hline & & 0.00 & 0.00 & 0 & الرتب الموجبة & & & & \\
\hline & & & & 0 & العلاقات & & & & \\
\hline & & & & 8 & الاجمالي & & & & \\
\hline
\end{tabular}

يتضح من جدول (2) أن قيمة (ويلكوكسون) لحساب دلالة الفروق بين منوسطي رثب القياسين القبلي والبعدي للمجموعة التجريبية على بعض المتغيرات الفسيولوجية (النبض في الراحة،

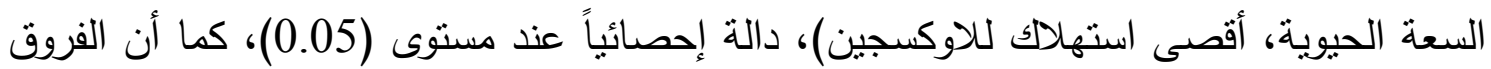
بين المتوسطات في القياسين القبلي والبعدي للمجموعة التجريبية على بعض المتغيرات الفسيولوجية

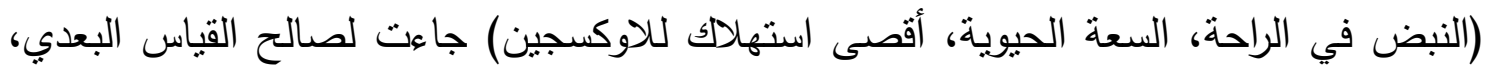

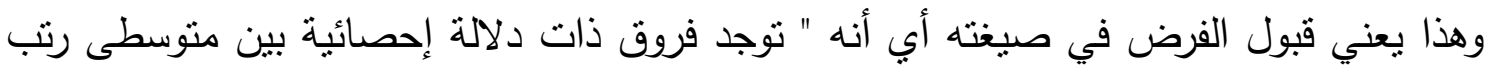

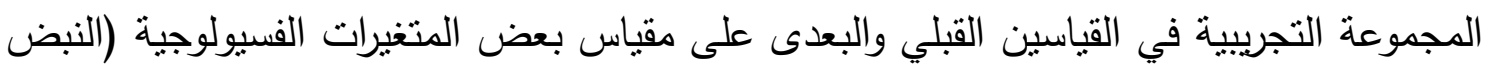


في الراحة، السعة الحيوية، أقصى استهلاك للاوكسجين) بعد تطبيق البرنامج في اتجاه القياس

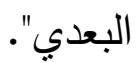

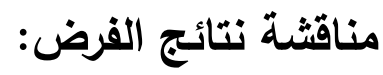

وقد يرجع الباحثون وجود فروق ذات دلالة إحصائياً لصالح القياس البعدي في المتغيرات قيد

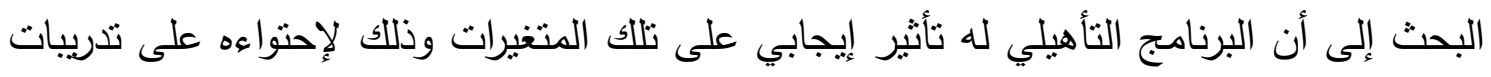

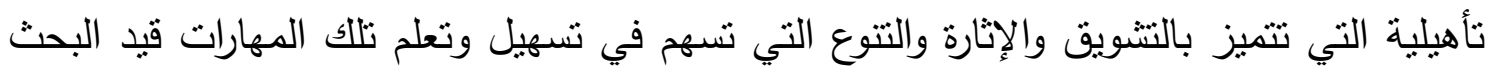

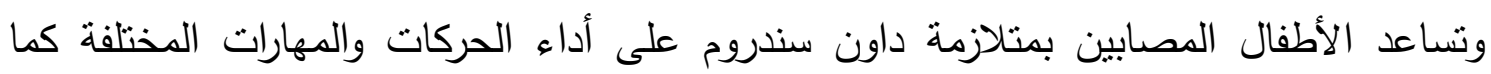

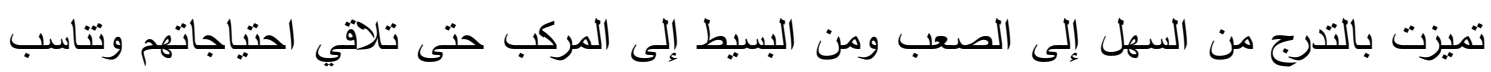

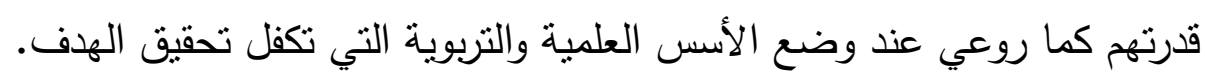

وهذا ما أكدته دراسة محمد حسن محمد عبدالحفيظ (2015) ان النشاط البدني يودي الى رفع مستوى اللياقة البدنية المرتبطة بالصحة وبعض المتغيرات الفسيولوجية لدى الأطفال المصابين

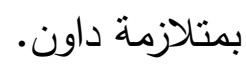

ويوضح الباحثون ان البرامج التأهيلية لابد وأن تتسم بالتدرج في الإرتقاء بالمستوى الحركي

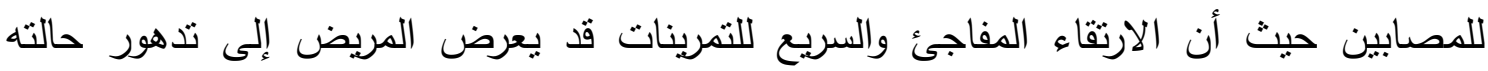
الصحية وخاصة في التعامل مع حالات تأهيل الأطفال.

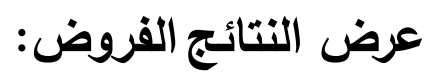

والذي ينص على "توجد فروق ذات دلالة إحصائية بين منوسطى رتب المجموعة التجريبية في القياسين القبلي والبعدى على مقياس بعض المتغيرات البدنبة بعد نطبيق البرنامج في اتجاه

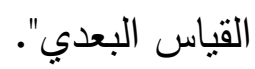

للتحقق من هذا الفرض قام الباحثون بحساب دلالة الفروق باستخدام اختبار (ويلكوكسون) لعينتين مرتبطتين في القياس البعدي في أبعاد الثفقة بالذات: اللطف بالذات، الحكم الذاتي، الانسانية المشتركة، العزلة، اليقظة العقلية، التوحد المفرط، والدرجة الكلية، كما يتضح من

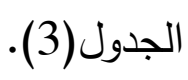




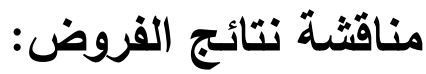

وقد يرجع الباحثون وجود فروق ذات دلالة إحصائياً لصالح القياس البعدي في المتغيرات قيد

البحث إلى أن البرنامج التأهيلي له تأثثر إيجابي على تلك المتغيرات وذلك لإحتواءه على تدريبات تأهيلية التي تتميز بالتنشويق والإثارة والتنوع التي نسهم في تسهيل وتعلم تلك المهارات قيد البحث وتنـاعد الأطفال المصـابين بمتلازمـة داون سندروم على أداء الحركات والمهارات المختلفة كمـا تميزت بالتدرج من السهل إلى الصعب ومن البسيط إلى المركب حتى تلاقي احتياجاتهم وتتاسب قدرتهم كما روعي عند وضع الأسس العلمية والتزبوية التي تكفل تحقيق الهذف. وهذا مـا أكدته دراسـة محمد حسن محمد عبدالحفيظ (2015) ان النشاط البدني يودي الى لى رفع مستوى اللياقة البدنية المرتبطة بالصحة ويوضح الباحثون ان البرامج التأهيلية لابد وأن تتسم بالتدرج في الإرتقاء بالمستوى الحركي للمصابين حيث أن الارتقاء المفاجئ والسريع للتمرينات قد يعرض المريض إلى تدهور حالته الصحية وخاصة في التعامل مع حالات تأهيل الأطفال.

الاستتتاجات:

في ضـوء هدف البحث، وفرضـه وفي حدود مجتمـع وعينة البحث، ومـن خـال الأدوات

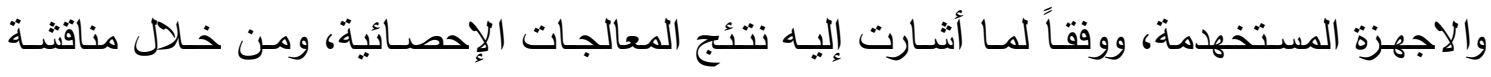
النتائج، تمكن الباحثون من التوصل إلى الاستتناجات التالية:

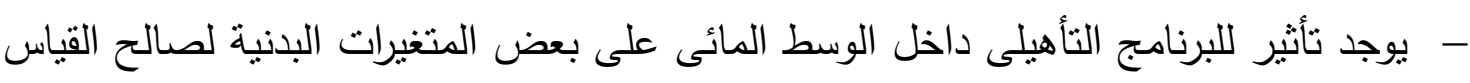
البعدى لعينة البحث.

التوصيات:

استتاداً إلى النتائج و الاتسخلاصـات التي توصل إليها الباحثون من خـلال هذا البحث يوصي الباحثون بما يلي: - الاسترشاد بالبرنامج التأهيلي المقترح في تأهيل الاطفال المصابين بمتلازمة داون سندروم. - إجراء دراسات وأبحاث مشابهة على الأطفال المصابين بمتلازمة داون سندروم للإرتقاء بمستوى حركاتهم إلى أقرب درجة طبيعية مقارنة بأمثالهم.

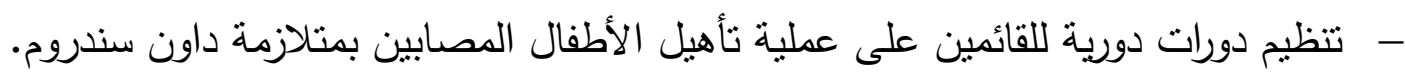


- - إنشاء قسم التأهيل الحركي لذوب الإحتياجات الخاصة بكليات التربية الرياضية. - تتفيذ البرنامج الترويحى المائي المقترح لتتمية القدرات الحركية الأساسية لأطفال هذه المرحلة على الجمعيات المعنية برعاية الفئات الخاصة.

- إعادة النظر فى البرامج الرياضية ونسبة ما تحويه من القدرات الحركية الأساسية بالنسبة للمرحلة السنية (6 -9) سنوات، والاسترشاد بالبرنامج المقترح.

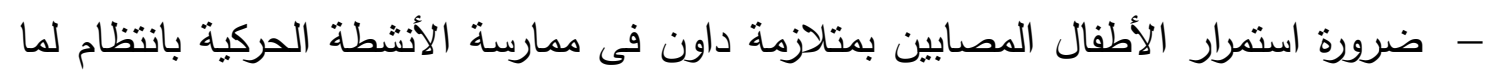
لها من أثر إيجابى على لياقتهم البدنية وأيضاً تحسين كفاءتهم المهنية.

قائمة المراجع أولا: المراجع العربية : : برنامج تأهيلي لتحسين درجة تشوة التقعر القطني

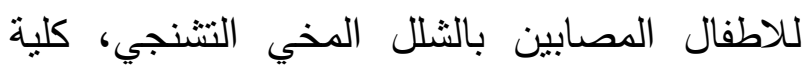
1 . أحمد خضر محمد السيد عمر(2015) التربية الرياضية، جامعة طنطا. 2. أحمد محمد رشدي (2017) : أثز استخدام برنامج تأهيلي على مستوى الأداء

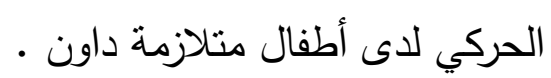

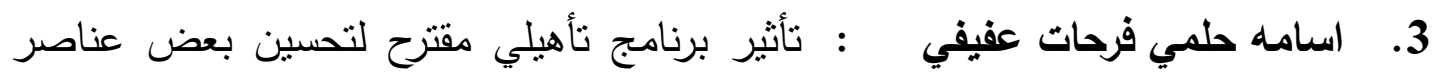

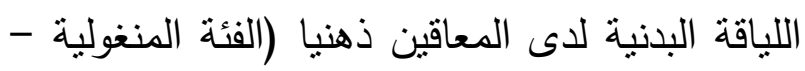

$$
\text { متلازمة داون). }
$$

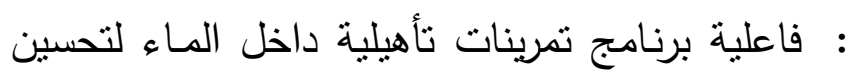
الحالة القوامية اللياقة البدنية لدي المعاقين ذهنياً.

4. - أمال جمعة محمود أحمد (2005)

: اثز استخدام أسلوب التمرينات المشابهة لتحسين 5. بعض مهارات القوة والثبات للاعبي الجمباز"، رسالة ماجستير ، كلية التربية الرياضية، جامعة الإسكندرية.

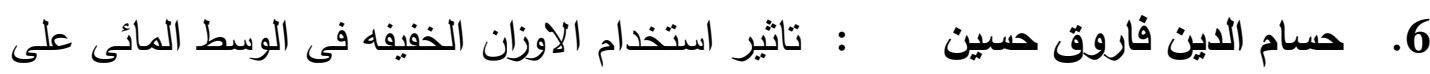

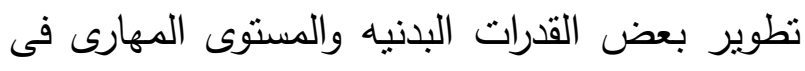
السباحه"، رسالة ماجستير ، غير منشورة، كلية التربية الرياضية بنات، القاهرة. 
: ت تأثثر برنامج تدريبي باستخدام التمرينات النوعية على :

7.

تحقيق منطلبات التزقي للحزام الأسود (دان

(2007)

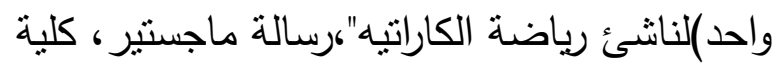

التربية الرياضية ،جامعة المنصورة،2007.

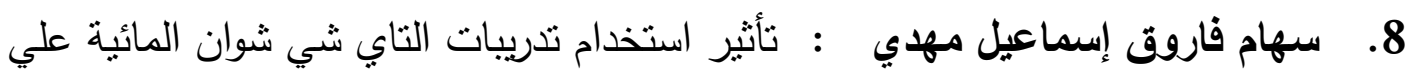

بعض المتغيرات البدنية والفسيولوجية لدي طالبات

(2009)

كلية التربية الرياضية.

(التدريب الرياضى التكامل بين النظرية والنطبيق،

9. عادل عبد البصير (1996)

المكتبة المتحدة، بور فؤاد.

: موسوعة التمرينات الرياضية،دار الفكر، ط2،الأردن.

10. - عبد المنعم سليمان برهم،

ومحمد خميس أبو نمره

(1988)

: التدريب الرياضي - نظريات وتطبيقات ، منشاة

$$
\text { المعارف ، الإسكندرية. }
$$

11. عصام الدين عبد الخالق

مصطقى(1994)

: تأثير برنامج تدريبي على تتمية الصفات البدنية والمهارية الخاصة بلاعبي الكاراتيه"، رسالة دكتوراه، كلية التربية الرياضية ، جامعة طنطا، 2001م.

12. عماد الدين عبد الفتاح

$$
\text { السرسي(2001) }
$$

13. محمد أحمد فؤاد حجازى

(2019)

بعض المتغيرات الفسيولوجية والقدرات الحركية لدى

أطفال متلازمة داون، رسالة ماجستير، كلية التربية

: علم التذريب الرياضي، دار المعارف،القاهرة.

14. محمد حسن علاوي(1990)

: دور برنامج الرعاية التربوية الخاصة فى تحقيق

15. مسعودة بنقيدة (2008)

السلوك التكيفى لاى الأطفال ذوى متلازمة داون،

رسالة ماجيستر، كليةالعلومالإنسانية والإجتماعية،

جامعة الجزائر الرياضية، جامعة دمياط. 
16. هشام صبحي حسن(1993) : نتأثير برنامج مقترح باستخدام بعض الأجهزة

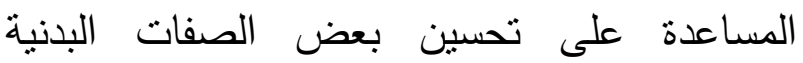

الخاصة ومستوى أداء التلويحة الدائرية على جهاز

حصان الحلق للناشئين"، رسالة دكتوراه ، كلية التربية

الرياضية للبنين، جامعة المنيا.

: فاعلية التعليم النوعي وعلاقته بتطوير مستوى الأداء

17. هيثم محمد احمد حسنين

لمبندئي السباحة"،رسالة ماجستير ،كلية التربية

(2005)

الرياضية للبنين ببنها، جامعة بنها.

ثانيا : المراجع الأجنبية

18. Jane Katz (1995) : Water fitness during your pregnancy, Human kinetics, U.S.A,

19. Borensteion (1996)

20. Astrand (1977) : Age changes in the anthropometric and body composition characteristics of the Bishnupriya Manipuris of Cachar district, Assam 
يهدف البحث إلى معرفة تأثثر التدريبات النوعية على بعض المتغيرات البدنية والفسيولوجية في السباحة لأطفال متلازمة داون، وقد استخدم الباحثون المنهج التجريبي نظرًا لملائمته لطبيعة البحث وقد تم اختبار عينة البحث (10) وتم إختبارهم بالطريقة العددية وتم إختيار 10 مصابين لتطبيق الدراسة الإسنطلاعية من خارج عينة البحث الاساسية وتراوحت اعمارهم من (8: 15 سنة) وكانت اهم الإستتناجات التي توصل إليها الباحثون ان البرنامج المقترح قد ادى إلى تحسن إيجابي في القوة العضلية لأطراف النصف العلوي والسفلي، وأن البرنامج المقترح قد أدى إلى تحسن إيجابي شامل على بعض المتغيرات البدنية، وكانت اهم توصيات الباحثون تتشيع الاطفال واولياء الأمور على ضرورة التأهيل المائي وممارسة الأنشطة داخل الماء وتتفيذ البرنامج بما يتتاسب مع كل حالة على حدا.

\begin{abstract}
The research aims to know the effect of specific exercises on some physical variables in swimming for children with Down syndrome, and the researcher used the experimental approach due to its suitability to the nature of the research. The research sample (10) was chosen by the intentional method and 2 patients were chosen to apply the exploratory study from outside the basic research sample. Their ages ranged from (8:15 years) and the most important conclusions reached by the researcher were that the proposed program had led to a positive improvement in the muscle strength of the upper and lower hemispheres, and that the proposed program had led to an overall positive improvement on some physical variables, and the most important recommendations of the researcher were Encouraging children and parents on the necessity of water rehabilitation, the practice of activities inside the water, and the implementation of the program in proportion to each case separately
\end{abstract}

